\title{
Sense of Belonging in Computing: The Role of Introductory Courses for Women and Underrepresented Minority Students
}

\author{
Linda J. Sax ${ }^{1}$, Jennifer M. Blaney ${ }^{1, *}$, Kathleen J. Lehman ${ }^{1}$, Sarah L. Rodriguez ${ }^{2}$ (D), \\ Kari L. George ${ }^{1}$ and Christina Zavala ${ }^{1}$ \\ 1 Graduate School of Education \& Information Studies, University of California, Los Angeles, CA 90095, USA; \\ lsax@ucla.edu (L.J.S.); jmblaney@ucla.edu (J.M.B.); kate.j.lehman@gmail.com (K.J.L.); \\ kgeorge85@ucla.edu (K.L.G.); zavalac@ucla.edu (C.Z.) \\ 2 School of Education, Iowa State University, Ames, IA 50011, USA; srod@iastate.edu \\ * Correspondence: jmblaney@ucla.edu
}

Received: 3 May 2018; Accepted: 21 July 2018; Published: 25 July 2018

\begin{abstract}
This study examines an aspect of gender and racial/ethnic gaps in undergraduate computing by focusing on sense of belonging among women and underrepresented minority (URM) introductory computing students. We examine change in sense of belonging during the introductory course as well as the predictors of belonging, with attention to conditional effects by gender and URM status. Results show that sense of belonging outcomes are a product of both incoming student characteristics and college environments and experiences, highlighting the important role the computing faculty play in fostering belonging. These and other findings are discussed, focusing on sense of belonging among women, URM students, and URM women.
\end{abstract}

Keywords: computer science; introductory computing; gender; URM students; race/ethnicity; sense of belonging

\section{Introduction}

\subsection{Purpose}

Despite national efforts to diversify computing in recent years, undergraduate computing programs remain remarkably un-diverse. Indeed, while women constitute over half of all college graduates (National Center for Education Statistics 2017), they comprise only 20\% of those earning bachelor's degrees in computing fields (National Science Foundation, National Center for Science and Engineering Statistics 2017a). While the representation of underrepresented minority (URM) students among computing degree recipients $(21 \%)$ is actually similar to their representation among degree earners from all fields (23\%) (National Center for Education Statistics 2017; National Science Foundation, National Center for Science and Engineering Statistics 2017a), they nevertheless experience computing as members of a minority group. Further, women and URM students often face negative stereotypes about their ability to succeed in computing (Cheryan et al. 2009; Margolis et al. 2008) and are more likely to perceive the climate in computing as racist or sexist (Barker et al. 2009). This may be particularly important to consider for women from URM groups, as they face negative stereotypes in computing related to both their gender and race.

Some scholarship has suggested that one of the reasons why women and people of color opt out of computing disciplines is a sense that they do not belong in the field (Barker et al. 2010; Cohoon 2002; Margolis and Fisher 2002). Indeed, in discussions of diversity in the tech industry, sense of belonging has been identified as a key component of diversity and inclusion efforts (Chu 2017). 
Within the higher education literature, sense of belonging is a known predictor of success in college (e.g., Freeman et al. 2007; Pittman and Richmond 2008; Strayhorn 2012), especially within STEM disciplines (Espinosa 2011; Johnson 2012). Sense of belonging refers to the extent to which individuals feel like they belong or fit in a given environment. College students who feel a greater sense of belonging are more connected to their environment and are more likely to persist to graduation (Strayhorn 2012). Sense of belonging can be characterized as feeling valued, cared about, and connected to one's college environment. Understanding sense of belonging in relationship to underrepresented students is essential, as past research has shown that students from stigmatized groups are more likely to experience uncertainty about their belonging and potential than majority students (Walton and Cohen 2007). More broadly, sense of belonging is conceptualized as a fundamental human need that drives students' behaviors, particularly in environments where they may feel that they do not belong (Baumeister and Leary 1995; Strayhorn 2012). Applying this to the computing context, women and URM students experience computing environments differently due to sexism and racism, both historically and as part of the current culture (Barker et al. 2009; Margolis and Fisher 2002; Margolis et al. 2008; Strayhorn 2012), potentially leading them to feel unwelcome and lack a sense of belonging to computing spaces. Students who experience uncertainty and distress about their belonging are left with less time to spend on their academics as the time and energy they could put into learning and building connections is spent on concerns that they do not belong in their field or major (see Strayhorn 2012).

It is clear that sense of belonging is important to the success of all college students, particularly those from underrepresented groups. Higher education research and theory emphasizes the importance of incoming orientations and background characteristics and their alignment with college environments in shaping the way students experience belonging (see Strayhorn 2012). Further, within computing, sense of belonging may play a key role in students' decision to pursue and persist in computing (Barker et al. 2010; Cohoon 2002; Margolis and Fisher 2002). With respect to computing student persistence, Barker and her colleagues (2014) underscore the importance of classroom experiences in relationship to sense of belonging, arguing that "classrooms are the predominant venue in which students are exposed to ... knowledge, presentation, and expectations about the kinds of people who belong (or not) in a degree program. How faculty talk about students in class helps to cement students' views of whether they belong (or not) ... [Feeling] that one doesn't belong, combined with being a minority in the classroom and confronting various gendered stereotypes, results in a loss of confidence for women, which can then lead to switching major" (Barker et al. 2014a, p. 2). Introductory courses may be particularly important to fostering a sense of belonging, as they may be students' first exposure to their chosen field and may shape the extent to which they find a fit with that major. As such, prior studies have shown that introductory courses are key to students' success and persistence in STEM fields, including computing (Gasiewski et al. 2012; Seymour and Hewitt 1997; Tobias 1990). For women and URM students, introductory courses in computing have the ability to enhance their sense of belonging, making them feel included in the computing community, or further marginalize them from this community, effectively pushing them out of the computing space.

While there is ample support for the importance of sense of belonging, little is known about the factors that contribute to the development of sense of belonging in the context of computing generally or within introductory computing courses specifically. Among the studies that do exist, most of them only consider sense of belonging and its impact on women (e.g., Beyer et al. 2004; Cheryan et al. 2009). Fewer studies have examined sense of belonging among URM students pursuing computing, and very little is known about URM women's sense of belonging in computing. Hence, more research is needed that addresses sense of belonging for women and URM students in computing, with consideration of classroom and departmental experiences, particularly within the context of introductory computing courses.

Understanding more about sense of belonging among women and URM students in undergraduate computing might be a first step towards creating more inclusive environments in 
the tech world. That is, students who experience relatively inclusive college computing environments early on may be more likely to seek out or replicate those environments when they move into more advanced coursework and their careers after college. Thus, there is a growing need for research to consider how women and URM undergraduates in early-stage computing courses develop their feelings of belonging in computing.

This study contributes to what is known about how colleges can foster sense of belonging in introductory computing courses, particularly among women and URM students. The following questions frame this inquiry.

1. How do incoming introductory computing students report their sense of belonging in computing, and how might this vary by gender and URM status?

2. How does sense of belonging in computing change during an introductory computing course, and how does this vary by gender and URM status?

3. What background characteristics and college experiences predict sense of belonging at the end of an introductory computing course, and do these predictors vary by gender and URM status?

\subsection{Literature Review}

Several bodies of literature provide a frame for the present work. Below, we synthesize the prior literature related to women and URM students' representation in computing and technology, the role of curricular and introductory course experiences, and prior research on sense of belonging, both generally and in computing.

\subsubsection{Women and URM Students in Computing}

There is a growing body of research related to women and URM students in undergraduate computing. Much of this research has focused on individual factors that may impact students' participation in the field. For example, research has shown that factors like women's and URM students' relative inexperience with programming (Beyer et al. 2003; Margolis and Fisher 2002), their tendency toward lower confidence in their computing abilities (Beyer 2014; Cheryan et al. 2016; Wilson 2002), and their tendency to view careers in computing as poor match with their personal values (Beyer et al. 2003, 2004; Carter 2006; Diekman et al. 2010) are all key reasons why women and URM students pursue computing at a lower rate than their male and/or majority peers.

However, framing the problem in terms of the individual characteristics of women and URM students places the blame on individuals and fails to acknowledge structural inequities that also shape underrepresented students' interest in computing. Margolis and Fisher (2002) argued that structural disparities amount to "weighty influences that steal women's interest in CS [computer science] away from them" (p. 6). Therefore, research must consider both individual differences as well as structural factors-such as computing departments and classrooms-to understand why more women and URM students do not pursue and persist in computing fields.

\subsubsection{Curricular Experiences in Computing}

Some scholars contend that student-centered pedagogical and curricular practices are critical to women's success in computing (Barker and Cohoon 2009; Cohoon and Aspray 2008). Indeed, most of the research on classroom practices shows that student-centered approaches, such as pair programming and collaborative learning, are beneficial for all students, regardless of gender or race/ethnicity (Barker et al. 2014b; Radermacher and Walia 2011; Settle 2012; Werner et al. 2005). Introductory STEM courses are often academically challenging and designed to "weed-out" students. Prior research has shown that these "barrier courses" are a key reason why students leave STEM fields (Seymour and Hewitt 1997). Further, students' perception that a course is meant to weed students out shapes their performance in said course (Suresh 2006); therefore, it seems likely that a weed-out culture might also impact students' sense of belonging in their chosen field. To be sure, not all introductory 
computing courses are designed to weed-out students; the computing field is making significant efforts to encourage participation from groups historically underrepresented in computing (e.g., women, URM students, and those lacking prior computing experience), which has included efforts to make introductory courses more inclusive (Alvarado et al. 2012).

Some research outside of STEM disciplines has pointed to the important role that early coursework plays in fostering a sense of belonging in higher education, also emphasizing the importance of student-centered pedagogies. More specifically, this work has highlighted the importance of feeling comfortable speaking up in class, student-faculty interactions, and peer relationships (Hoffman et al. 2002). To provide students such opportunities in introductory computing courses, some instructors have implemented practices such as employing a flipped classroom teaching model and incorporating peer instructors.

Prior work has also emphasized the importance of introductory course experiences for women and URM students. Barker et al. (2014b) assert that modifications to introductory computing courses are a key component of recruiting more women to computing through the use of inclusive curricular and pedagogical practices. For instance, they suggest that instructors should seek to make courses relevant by aligning assignments and coursework to students' interests and career goals. In other STEM fields, researchers have documented the important role that introductory courses can play in promoting student engagement in the discipline (Gasiewski et al. 2012), recruiting and retaining students in STEM majors (Graham et al. 2013; Hoisch and Bowie 2010), and developing STEM aspirations (Perna et al. 2009).

\subsubsection{Sense of Belonging}

Sense of belonging is one way to measure the extent to which students feel like they "fit" in a given environment. Specifically, in a classroom context, sense of belonging may be defined as "students' sense of being accepted, valued, included, and encouraged by others (teachers and peers) in the academic classroom setting and of feeling oneself to be an important part of the life and activity of the class" (Goodenow 1993, p. 25). Studying sense of belonging is useful because it allows researchers to measure how college students' experiences shape their affiliation with their environment (Hurtado and Carter 1997).

Research on sense of belonging among college students has found that it is key to their success and retention in college (e.g., Freeman et al. 2007; Pittman and Richmond 2008; Strayhorn 2012). However, this literature has found that students from underrepresented groups tend to have a lower sense of belonging than their counterparts from majority groups and thus face additional obstacles and barriers to their success and retention in college (Hurtado and Carter 1997; Johnson et al. 2007; Strayhorn 2012). Research has also investigated sense of belonging among STEM undergraduate students. Johnson (2012) work suggests that STEM students are more likely to feel a sense of belonging when they have high levels of academic self-confidence and encounter academically and socially supportive environments. Research on STEM students' sense of belonging also highlights the importance of belonging for underrepresented groups (Espinosa 2011; Johnson 2012; Thoman et al. 2014). Johnson (2012) found that women of color in STEM had lower sense of belonging compared to their counterparts from other groups. Additionally, women and URM students may perceive a lack of fit between their identities or values and a major or career in STEM (Diekman et al. 2010; Smith et al. 2014); this mismatch may further augment a false sense that they do not belong. In turn, as is suggested by the work of Thoman and colleagues (2014), sense of belonging (or a lack thereof) can work as a force to push women out of STEM fields, where they may feel low levels of belonging, and toward non-STEM fields where they are more likely to feel a sense of fit. Indeed, Espinosa (2011) found that sense of belonging was significantly related to STEM retention, particularly for women of color. 


\subsubsection{Sense of Belonging in Computing}

While there is a large body of literature examining sense of belonging among college students including those in STEM fields, the literature on sense of belonging in computing is limited, and little is known about women and URM students' experiences with sense of belonging in computing disciplines. Of the research that does exist in this area, researchers have documented the importance of sense of belonging, finding that a strong sense of belonging in computing helps students persist, even when they have doubts about their abilities in the discipline (Veilleux et al. 2012).

While little is known about how sense of belonging develops among computing students, some research has found that the physical environment of a computer science classroom can communicate stereotypes about the field that women do not belong, negatively affecting women's interest in pursuing a computing major (Cheryan et al. 2009). Further, these stereotypes about who does and does not belong in computing have been found to be detrimental to women's and URM students' interest and persistence in computing (Beyer et al. 2004; Cheryan et al. 2013; Margolis and Fisher 2002).

\subsubsection{Gaps in the Literature}

Little empirical research has been conducted to investigate the role of curricular experiences in computing students' sense of belonging and how these experiences may differentially impact women and URM students. While some research has shown that student-centered teaching practices are beneficial for student outcomes, researchers have not yet investigated the impact of these practices on students' sense of belonging in computing. This paper pulls these areas of research together to examine the role of gender and URM status in shaping how sense of belonging develops during introductory computing, focusing on the course environments that predict more positive sense of belonging outcomes.

\subsection{Conceptual Framework}

Our analysis was guided by Strayhorn (2012) model of sense of belonging. In the case of college, sense of belonging can be defined as a student's perceptions of campus supports, experiences of feeling cared about, and connectedness with faculty, staff, and peers. Sense of belonging among students is influenced by incoming perceptions of belonging and can change over time as environmental contexts and circumstances shift. As this model suggests, how students experience the academic and social systems of the institution influences sense of belonging and, in turn, retention and persistence decisions. Students who feel a sense of belonging tend to feel more connected to their environments and are more successful, while students who do not feel a sense of belonging are more likely to experience alienation, disengagement, and depart the college environment.

Strayhorn suggests that sense of belonging takes on heightened importance in certain contexts, at certain times, and among certain populations, particularly in contexts in which students feel marginalized. The model addresses sense of belonging for college students as a function of the social spaces and contexts of the institution and outlines outcomes related to positive and negative experiences with sense of belonging. Multi-dimensional in nature, a student's sense of belonging is the result of a variety of individual and institutional factors including those related to incoming values and orientations, academic engagement, peer and faculty relationships, and departmental and campus climate (Freeman et al. 2007; Johnson et al. 2007; Locks et al. 2008; Nuñez 2009; Strayhorn 2008). The present study focuses specifically on sense of belonging in the field of computing. Strayhorn (2012) work further emphasizes that the intersection of social identities, such as gender and race, affect college students' sense of belonging which, in turn, can affect other outcomes, such as engagement, achievement, well-being, happiness, and optimal functioning, particularly for women and students of color in STEM fields.

This study utilized concepts identified by Strayhorn to examine how a student's sense of belonging in computing evolves during an introductory computing course and how changes in belonging may 
or may not vary by gender and URM status. Specifically, Strayhorn's model of sense of belonging determined the variables used in the study and how subsequent findings and implications were developed. Further, Strayhorn guided the focus of this study on conditional effects and how sense of belonging might develop differently depending on the one's social identities.

\section{Materials and Methods}

\subsection{Data and Sample}

This study utilized data from undergraduate students enrolled in introductory computing courses during the 2015-2016 academic year at 15 universities across the United States. ${ }^{1}$ The participating institutions are part of the Building Recruiting and Inclusion for Diversity (BRAID) project focused on improving recruitment and retention of underrepresented students in computing. The 15 institutions primarily represent large research universities, including 2 private and 13 public institutions. Notably, the computing department chair at each of the 15 institutions volunteered their institution to be part of the project, and so the institutions represent a self-selected group where the department chair has expressed some level of interest in diversifying their department. To identify eligible survey participants, we allowed the 15 participating computing departments to identify the courses they consider to be introductory. Our departmental contacts then provided us a list of contact information for all students enrolled in those courses, yielding a potential sample of 11,944 introductory computing students. A pretest survey was administered to those 11,944 students during the first two weeks of the course and resulted in a response rate of $32 \%(n=3814)$. A post-test survey was administered at the end of the course. Of the students who completed the pretest, $36 \%$ also completed the post-test survey, yielding a matched sample of 1,355 students. The surveys were developed in collaboration with the Computing Research Association's Center for Evaluating the Research Pipeline (CERP) and pilot tested with a focus group of computing students. Both surveys were administered online. Additionally, we incentivized participation by rewarding the first 400 participants with a \$15 Amazon gift card upon completion of the survey; all participants were also entered in a raffle to win one of two \$125 Amazon gift cards. The same incentive structure was used for both surveys.

Among the matched sample, $76.0 \%$ of participants were students from racial/ethnic groups considered a "majority" in computing (50.6\% White, 21.8\% Asian, 1.6\% two or more majority races), and the remaining 24.0\% were URM students (5.5\% Black; 9.2\% Hispanic; 0.7\% Native American; $0.2 \%$ Native Hawaiian; $1.7 \%$ Arab, Middle Eastern, or Persian; $6.4 \%$ two or more races with at least one URM identity). Women, in general, represented $42.1 \%$ of the sample, with URM women accounting for $25.5 \%$ of female respondents. The majority of students were in their first $(44.2 \%)$ or second $(23.9 \%)$ year in college, and approximately half $(48.0 \%)$ of students entered the course with a computing major. Students were asked on the pretest survey to indicate their reason(s) for enrolling in the course; notably, three-quarters of our sample (70\% of women and $78 \%$ of men) indicated that they enrolled to fulfill a major requirement, and about half of all respondents ( $47 \%$ of women and $48 \%$ of men) said that they enrolled because of curiosity or interest in computers. ${ }^{2}$

Before conducting regression analyses, we deleted cases that had missing data on key variables (e.g., gender). Next, we determined that less than 5\% of data was missing and results from Little's Missing Completely at Random (MCAR) test revealed that data was missing at random; thus, we used Expectation-Maximization to replace missing data, resulting in an analytic sample of 939 students for the regression analysis.

1 For the purposes of this paper, computing refers to the following: Computer Science, Computer Information Systems/Informatics, Bioinformatics, Computing and Business, Information Technology, Data Science, Game Design, Computer/Software Engineering, or Other Computing.

2 To determine students' reasons for enrolling in the course, students responded to the following question on the pretest survey: Why did you enroll in an introductory computing class? Select all that apply. It was required for my major; Curiosity or interest in computers; My parents encouraged me to; A teacher or other mentor encouraged me to. 


\subsection{Measures}

\subsubsection{Dependent Variable}

The outcome variable is a three-item measure of sense of belonging based on respondents' agreement with the following: "I feel like I 'belong' in computing", "I feel like an outsider in the computing community" (reverse-coded), and "I feel welcomed in the computing community". Students responded to each of these items on a five-point scale $(1=$ strongly disagree, $5=$ strongly agree). This measure was developed in consultation with CERP and is based on established measures of sense of belonging (e.g., Good et al. 2012; Hurtado and Carter 1997) to focus on the computing context; importantly, prior research has documented the importance of measuring domain-specific sense of belonging (Lewis et al. 2016).

For descriptive analyses, sense of belonging was measured by adding the three items together to create a scale ranging from 3 (low sense of belonging) to 15 (high sense of belonging). For regression analyses, we computed a factor using principal axis factoring, which was standardized and centered at the mean. The Cronbach's alpha for this measure is 0.726 , and factor loadings are shown below in Appendix A, Table A2.

\subsubsection{Independent Variables}

Independent variables are drawn from both the pretest and post-test surveys and were selected in accordance with Strayhorn (2012), described above. Specifically, we identified three categories of variables highlighted by Strayhorn (2012): (1) background characteristics, which included a direct pretest of the dependent variable, demographics, prior academic experiences; (2) incoming orientations; and (3) college environment experiences, which included: feelings of support on campus, student behaviors, and classroom experiences. The specific variables in each of these three categories are described below. Descriptive statistics for all independent variables are included in Table A1, and all composite measures are further described in Table A2.

\section{Background Characteristics}

First, we included a measure of sense of belonging at the beginning of the course, which served as a direct pretest for the dependent variable. This variable was treated as a control and was identical to the dependent variable (i.e., it included the same three items, which were used to create a factor). Our decision to include incoming sense of belonging as the first independent variable was guided by Astin and antonio (2012) who recommend controlling for the pretest before all other variables.

To measure gender, students were asked to select one of the following options: female, male, or non-binary/other. Due to small numbers of non-binary students, they are excluded from these analyses and gender was recoded as a dichotomous measure $(0=$ male; $1=$ female $)$. To measure race/ethnicity, students selected one or more of the following: White/Caucasian; African American/Black; American Indian/Alaska Native; East Asian; Southeast Asian; South Asian; Arab, Middle Eastern, or Persian; Other Asian; Native Hawaiian/Pacific Islander; Mexican American/Chicano; Puerto Rican; Other Latino; Other. From there, students were grouped into the following categories: White; Asian; African American/Black; Hispanic/Latino; Native American/Native Hawaiian/Pacific Islander; Arab, Middle Eastern, or Persian; two or more URM races; two or more majority races. Due to small sample sizes, we used a dichotomous measure of URM status for regression analyses $(0=$ Majority; $1=$ URM). Students identifying with at least one of the following were counted as URM: African American/Black; Hispanic/Latino; Native American/Native 
Hawaiian/Pacific Islander; or Arab, Middle Eastern or Persian. White/Caucasian and Asian students were coded as majority in the context of computing. ${ }^{3}$

Next, we included measures of parents' education level, parents' computing career, and socioeconomic status. To measure parents' education level and career, students were asked to indicate the highest level of education achieved by up to four parents as well as their parents' careers. From those responses, we computed a variable identifying the highest education of one of their parents, using the following categories: high school or less; some college, or associate's degree; bachelor's degree; or graduate/professional degree. Next, we computed a dichotomous measure indicating whether or not the student had at least one parent with a computing-related career. Socioeconomic status was measured on a 5-point qualitative scale ranging from poor to wealthy.

To capture prior academic achievement and experience, we included a measure of high school GPA and prior programming experience. As a proxy for high school GPA, students were asked to indicate their average high school grade on a 9-point scale $(1=\mathrm{D} ; 9=\mathrm{A}$ or $\mathrm{A}+)$. Prior programming experience was measured using a scale made up of seven items asking about previous programming experiences, described in Appendix A, Table A2. All background characteristics were measured using student responses to the pretest survey.

\section{Incoming Orientations}

Strayhorn (2012) model highlights the importance of incoming predispositions for college students pursuing STEM. To capture this, the study included pretest variables related to incoming leadership, artistic orientations, family and communal values, and scholar personality to add dimension to our understanding of a student's predispositions, which are essential to understanding incoming sense of belonging. When considering sense of belonging, these attributes may provide insight into not only how a student comes to the computing context, but also which values and orientations find congruence within the computing context and enable students to feel a sense of belonging within their surroundings. If students believe that their values and orientations toward concepts including leadership, art and creativity, family, and scholarly activities do not align with the computing environment in their institution or the field at-large, they may be more likely to feel a sense of alienation, disengagement, and desire to leave that environment.

These variables were all measured using pretest survey items that were used to develop composite variables. Each of these composite variables is described in Table A2. For variables made up of two items, those items were added together to create a scale. Variables made up of three or more survey items were made into factors using principal axis factoring. All of these items were measured using survey responses to our pretest survey and serve as bridge variables, linking background characteristics to the college environment experiences described below. All factors and scales were mean-centered and standardized.

\section{College Environment Experiences}

We included three groups of variables related to college environment experiences: general feelings of support on campus, student behaviors, and classroom experiences. Strayhorn (2012) alludes to the importance of considering students' experiences in different academic and social spaces within the college environment. Accordingly, we included measures of departmental support and peer support, both of which were composite variables described in Table A2. The departmental support variable was made up of students' general reports of the extent to which they perceived their computing department to be supportive (e.g., cares about students). Peer support included items related to the

3 Tamer and Stout (2016) include African American/Black, Hispanic/Latino, Native American and Alaska Native, and Arab, Middle Eastern, or Persian students within the URM group in the context of computing. We also include Pacific Islander students in the URM group to be more consistent with the National Science Foundation's definition of URM (National Science Foundation 2017b). 
extent to which other computing students provided the respondent with different aspects of academic support (e.g., help with difficult homework problems) and personal support (e.g., someone to discuss problems with).

Student behavior variables were included next and focused on how students spend their time. Specifically, we used single-item measures where students reported the number of hours per week they spend on the following activities: computing-related student groups, studying/homework, playing video games, and using online social networks. Each of these variables was measured on an 8-point scale ranging from none to more than 20 hours per week.

Finally, this study also examined the role of classroom experiences including the instructor's use of collaborative pedagogies, class discussion, lecture, and relevant and meaningful content, as well as measures of instructor inclusivity and student-instructor communication. Use of class discussion and lecture were measured using single items, which asked how frequently the introductory course instructor used the respective practices on a 5-point scale ranging from never to always. Measures of collaborative pedagogies, relevant and meaningful content, and instructor inclusivity were created using principal axis factoring; factor loadings and Cronbach's alphas are included in Table A2. Lastly, student-instructor communication was measured using a composite scale that is also described in Appendix A. All variables related to college environments were measured using students' responses to our post-test survey.

\section{Results}

\subsection{Research Question One: Incoming Sense of Belonging by Group Identity}

\subsubsection{Procedure}

Strayhorn (2012) conceptual model for sense of belonging suggests that prior identities, backgrounds, and experiences may influence incoming feelings of belongingness to the college environment. Research question one asked about students' incoming sense of belonging in the field of computing and how that varies by gender and URM status. To address this question, we first examined the distribution of incoming sense of belonging scores. Next, we conducted independent sample t-tests to compare mean differences on incoming sense of belonging by gender and URM status. Finally, we wanted to further explore differences among specific subgroups of URM and majority students. To do this, we ran tests using one-way analysis of variance (ANOVA) to examine mean differences among: (1) URM subgroups (Black, Hispanic, Indigenous, Arab/Middle Eastern, and multiracial URM); (2) majority subgroups (White, East Asian, Southeast Asian, South Asian, and other Asian); and (3) gender and URM status as overlapping identities (i.e., URM women, majority women, URM men, majority men).

\subsubsection{Results}

Findings for research question one revealed differences in students' incoming sense of belonging by both gender and URM status. Women reported a significantly $(\mathrm{t}(958)=7.872, p<0.001)$ lower average incoming sense of belonging $(M=9.33, S D=2.53)$ than their male counterparts $(M=10.67$, $\mathrm{SD}=2.53)$. There were also significant differences by URM status $(\mathrm{t}(949)=2.664, p<0.01)$, with URM students reporting a higher average incoming sense of belonging $(\mathrm{M}=10.52, \mathrm{SD}=2.73)$ than their majority student counterparts $(\mathrm{M}=9.96, \mathrm{SD}=2.69)$.

Additionally, we examined mean differences among majority and URM subgroups using one-way ANOVAs. Specifically, we compared mean scores across the following URM groups (Black, Hispanic, Indigenous, Arab/Middle Eastern, and multiracial URM). Next, we compared means for the majority subgroups (White, East Asian, Southeast Asian, South Asian, and other Asian). We found no significant 
differences among the URM or majority subgroups. However, the lack of significant differences may be a result of small sample sizes for some subgroups. ${ }^{4}$

Given that women, on average, reported lower incoming sense of belonging, while URM students reported higher sense of belonging, we ran additional tests to examine gender and URM status as overlapping identities. As shown in Table 1, URM women reported an incoming sense of belonging that is lower than that of URM men, but a higher sense of belonging than White and Asian women. URM women did not significantly differ from majority men.

Table 1. Mean Differences in Incoming Sense of Belonging, by Gender and URM Status.

\begin{tabular}{cccc}
\hline Group & Mean & Std. Dev. & Sig. Diff. From \\
\hline (1) White and Asian Men & 10.59 & 2.55 & 2 \\
(2) White and Asian Women & 9.13 & 2.63 & $1,3,4$ \\
(3) URM Men & 10.96 & 2.48 & 2,4 \\
(4) URM Women & 10.00 & 2.92 & 2,3 \\
\hline
\end{tabular}

Note: $\mathrm{F}=23.587, p<0.001$.

\subsection{Research Question Two: Change in Sense of Belonging}

\subsubsection{Procedure}

Strayhorn (2012) model highlights the importance of sense of belonging as a feeling, which can shift over time due to changes in circumstances or context. To explore research question two, we used paired-sample t-tests to examine change in sense of belonging from the beginning to the end of the introductory course. Next, we calculated a change score variable by subtracting students' incoming sense of belonging score from their end-of-term sense of belonging score. This change score was then used in one-way ANOVA tests to examine differences for men and women as well as majority and URM students. Additionally, we used one-way ANOVAs to explore how change differed among (1) URM subgroups, (2) majority subgroups, and (3) gender and URM status together.

\subsubsection{Results}

Analyses of change over time revealed that sense of belonging significantly decreased among students overall ${ }^{5}$ (see Table 2. However, gender differences were evident, with significant declines in women's sense of belonging, but no significant change over time for men. Thus, the declines that we originally observed among students in general were due to declines among women only. While declines in women's sense of belonging were statistically significant, the effect size was quite small (Cohen's d $=0.114$ ), suggesting little practical significance. We found no differences between URM and majority students in terms of how sense of belonging changed during the intro computing course, with change over time being non-significant for both groups. We also examined whether change in sense of belonging differed for URM women compared to their counterparts (i.e., White and Asian men, White and Asian women, and URM men), or among disaggregated URM and majority groups. In all cases, the one-way ANOVAs showed no significant differences in change over time. However, the lack of significant differences may be a result of small sample sizes for some subgroups.

4 Sample sizes for majority subgroups are as follows: White $(N)=544$, East Asian $(N)=130$, Southeast Asian $(N)=59$, South Asian $(N)=58$, and Other Asian $(N)=4$. Sample sizes for URM subgroups are as follows: Black $(N)=49$, Hispanic $(N)=77$, Indigenous $(\mathrm{N})=6$, Arab/Middle Eastern $(\mathrm{N})=19$, and Multiracial $(\mathrm{N})=62$.

5 We ran additional tests to examine institutional differences within the sample. At some institutions, there were no significant changes over time, but this may be due to small sample sizes and a lack of statistical power. 
Table 2. Change in Sense of Belonging.

\begin{tabular}{|c|c|c|c|c|c|c|c|}
\hline & \multicolumn{2}{|c|}{ Incoming Belonging } & \multicolumn{2}{|c|}{ End of Term Belonging } & \multirow[b]{2}{*}{ df } & \multirow[b]{2}{*}{$\mathbf{t}$} & \multirow[b]{2}{*}{ Sig. } \\
\hline & Mean & SD & Mean & SD & & & \\
\hline All students & 10.06 & 2.71 & 9.92 & 2.96 & 972 & -2.067 & * \\
\hline Men & 10.66 & 2.54 & 10.63 & 2.87 & 527 & -0.368 & \\
\hline Women & 9.33 & 2.72 & 9.01 & 2.86 & 417 & -3.023 & $* *$ \\
\hline Majority & 9.95 & 2.69 & 9.80 & 2.96 & 729 & -1.919 & \\
\hline URM & 10.51 & 2.74 & 10.33 & 2.96 & 208 & -1.144 & \\
\hline
\end{tabular}

\subsection{Research Question Three: Predictors of Sense of Belonging}

\subsubsection{Procedure}

Within Strayhorn (2012) conceptual model, he suggested that inter-related concepts of context, experience, and identity predict how a student experiences sense of belonging in college and influences their decision to persist or depart the institution. To examine research question three, we used blocked linear regression to examine the predictors of sense of belonging in the computing field and interaction terms to test for conditional effects by gender and URM status. Variables were blocked in accordance with our conceptual framework described in the measures section above (i.e., each block of variables was entered one at a time). The pretest, gender, and URM status were forced into the model; all other variables were entered stepwise, so that only significant variables entered the model. Two-way interaction terms were computed by calculating the gender- or URM-based cross products for all incoming orientation variables and college environment experience variables. When two-way interaction terms were significant, we also tested for three-way interactions (i.e., IV * Gender * URM status) to examine the extent to which effects might be unique for URM women compared to URM men, majority women, and majority men. In the findings below, we first share the main effects (i.e., before interactions enter the model), followed by a discussion of the significant interaction terms.

\subsubsection{Results}

The final research question examined the factors that predict sense of belonging at the end of the introductory computing course and whether those predictors varied by gender or URM status. The main effects regression model is shown in Table 3 (with Appendix A, Table A3 providing further detail on changes in coefficients as each block of variables was added to the model). Our final model explained $62 \%$ of the variance in sense of belonging at the end of the course, though $52 \%$ of the variance was explained by the pretest of incoming belonging alone. Still, several variables entered the model even after controlling for the pretest of sense of belonging.

Table 3. Linear Regression Predicting Sense of Belonging in Computing $(n=939)$.

\begin{tabular}{ccccccc}
\hline Independent Variables & $\boldsymbol{R}^{\mathbf{2}}$ Change & $\boldsymbol{r}$ & Beta & $\mathbf{b}$ & Std. Error & Sig. \\
\hline Pretest & 0.521 & 0.721 & 0.530 & 0.545 & 0.025 & $* *$ \\
Gender: Woman & 0.011 & -0.276 & -0.108 & -0.224 & 0.044 & $* *$ \\
Race: URM & 0.000 & 0.074 & 0.016 & 0.039 & 0.051 & \\
Prior Programming Experience & 0.007 & 0.331 & 0.096 & 0.092 & 0.021 & $*$ \\
Communal Orientation & 0.000 & -0.020 & -0.072 & -0.074 & 0.022 & $*$ \\
Artistic Personality & 0.001 & 0.059 & 0.048 & 0.050 & 0.021 & \\
Departmental Support & 0.071 & 0.521 & 0.277 & 0.284 & 0.024 & $*$ \\
Peer Support & 0.004 & 0.318 & 0.065 & 0.067 & 0.023 & $*$ \\
\hline & Note: ${ }^{*} p<0.01 ; * *<0.001$. & & &
\end{tabular}

Characteristics that students bring with them to the introductory course significantly predict their sense of belonging at the end of the course. For example, students who come to the introductory course with more prior programming experiences tend to leave the course with greater sense of belonging, even after controlling for the pretest of incoming sense of belonging, gender, and all other variables in 
the model. In addition, having a communal orientation (i.e., placing high value on helping others and contributing to the community) predicted declines in sense of belonging by the end of the course.

Only two environmental variables entered the model. Namely, feeling supported by the department as well as by peers in computing were both positive predictors of the sense of belonging outcome. Notably, none of the introductory course experience variables were significant predictors in the final model. This may be due to the fact that general feelings of support from the department and peers in computing shared variance with these other introductory course experiences; perhaps some of these experiences led students to feel more or less supported by peers and the department, which then shaped sense of belonging outcomes. In fact, additional analyses revealed that being exposed to inclusive classroom pedagogies was positively correlated with more general feelings of support from the department $(r=0.405 ; p<0.001)$ and peers $(r=0.185, p<0.001)$. Perhaps it was the case that exposure to more inclusive pedagogical practices in the introductory course led students to feel more supported, thus increasing their sense of belonging.

The last half of research question three asked about how the predictors of sense of belonging might vary by gender and URM status. Tests for interaction effects revealed two significant interaction terms, both of which relate to the impact of artistic personality for women and URM students. Table 4 shows the standardized regression coefficients (1) when no interactions are included (i.e., main effects), and (2) when the artistic interactions are included. As shown in the table, tests for interactions by gender and URM-status revealed that having an artistic orientation was a positive predictor of sense of belonging for women (Beta $=0.303, \mathrm{t}(927)=3.531, p<0.01$ ) and URM students (Beta $=0.224$, $t(927)=2.607, p<0.01)$, but was not significant for men from majority racial/ethnic groups (i.e., White and Asian men). To further explore this result, we tested for three-way interactions (i.e., gender * URM * artistic personality), but none were significant.

Table 4. Main Effects and Interaction Effects Models Predicting Sense of Belonging ( $n=939$ ).

\begin{tabular}{ccccc}
\hline & \multicolumn{2}{c}{ Model of Main Effects } & \multicolumn{2}{c}{ Model with Artistic Interactions } \\
\hline & Beta & Sig. & Beta & Sig. \\
\hline Independent Variables & & & & $*$ \\
Pretest & 0.530 & $* *$ & 0.521 & $* *$ \\
Gender: Woman & -0.108 & $* *$ & -0.393 & $*$ \\
Race: URM & 0.016 & & -0.194 & $*$ \\
Prior Programming Experience & 0.096 & $* *$ & 0.098 & $*$ \\
Communal Orientation & -0.072 & $*$ & -0.070 & $*$ \\
Artistic Personality & 0.048 & & -0.037 & $*$ \\
Departmental Support & 0.277 & $* *$ & 0.278 & $*$ \\
Peer Support & 0.065 & $*$ & 0.063 & $* 303$ \\
Gender x Artistic & - & & 0.224 & $* .622$ \\
URM x Artistic & - & &
\end{tabular}

Note: ${ }^{*} p<0.01 ;{ }^{* *} p<0.001$. This table shows two different models predicting sense of belonging. Dashes indicate that the variable was not included in the model.

\section{Discussion}

At a time when the tech industry and undergraduate computing programs are engaged in intensified dialogue about diversity and inclusion, this study investigates one aspect of inclusion-a sense of belonging in the field of computing - and how that operates within introductory computer science courses, with particular attention to the role of gender and URM status. More specifically, this study examined how gender and URM status shape the way incoming introductory computing students report their sense of belonging in the field of computing, how their sense of belonging changed during their introductory computing course, and the background characteristics and college experiences that predict those changes. Our findings revealed differences in incoming sense of belonging by both gender and URM status. Gender differences also emerged in how sense of belonging changed during the course, with women experiencing declines in their sense of belonging over time, though the effect size was small (Cohen's $d=0.114$ ). Finally, findings pointed to the different factors 
that predict sense of belonging outcomes for all students, and women and URM students in particular. Many results from this study affirmed existing research on gender differences in sense of belonging in computing (e.g., Blaney and Stout 2017; Cheryan et al. 2009), while also adding to existing literature on this topic in key ways. As such, this study has implications for research, practice, and theory.

\subsection{Implications for Research}

First, women in introductory computing classes started out with a significantly lower sense of belonging in the field of computing than their male counterparts, and these differences became marginally greater as women experienced declines in their sense of belonging throughout the course (Cohen's $\mathrm{d}=0.114$ ). While a persistent gender gap in sense of belonging was expected, another result was more surprising: URM students actually reported a higher sense of belonging than their majority peers. Given other research documenting lower sense of belonging for URM students on campus (Johnson et al. 2007), more research is needed to understand this counterintuitive finding. We wonder whether the URM students pursuing computing represent a unique subset of URM students that are particularly impervious to unwelcoming higher education environments; perhaps that resilience and determination is what led them to pursue an undergraduate STEM field from the start (see Mitchell 2011). Further, the context examined in this study (research universities) may represent an environment that provided greater resources to support high-achieving underrepresented students in STEM. These conjectures merit a closer examination in future research, which should examine whether and how the type of postsecondary institution attended mediates the relationship between URM status and sense of belonging. Future research should consider racial/ethnic differences in sense of belonging even among students who do not pursue undergraduate computing. Further, as Strayhorn (2012) theorizes, different college environments (e.g., the classroom, department, and institution as a whole) shape how students develop their sense of belonging. Findings from the present study emphasize the importance of departmental climate (i.e., the impact of perceived peer and departmental support in computing). However, future research should also examine how computing students develop their sense of belonging within the context of the larger institution.

This study also provided insights into the factors that contribute to changes in sense of belonging in the field of computing from the beginning to the end of the introductory computing course. While classroom experiences did not significantly predict belonging, department-level experiences did contribute to introductory course students' sense of belonging within the computing field. Specifically, feeling supported by the computing department, as well as by peers, was central to fostering students' sense of belonging in the field of computing. As mentioned earlier, students who experienced inclusive pedagogies and course content also perceived greater support from peers and the department; thus, shared variance may explain why the introductory course experiences were not significant. As such, our findings suggested that these general supportive experiences with peers and departments might be more important than specific pedagogical practices, though being exposed to inclusive pedagogies may contribute to general feelings of support from peers and the department.

Indeed, results regarding "support" variables affirm many of the suggestions put forth by the National Center for Women \& Information Technology, which argues for a student-centered departmental change model when seeking to diversify undergraduate computing majors (Barker et al. 2014b; Barker and Cohoon 2009). Despite this, course-specific variables were not significant predictors of sense of belonging. Notably, our measure of collaborative pedagogy, which indicated the extent to which the course involved group work, paired programming, and peer instruction, did not contribute to students' sense of belonging above and beyond the effects of the support variables (perhaps due to shared variance, as suggested earlier). Perhaps collaboration and interactions with peers in the classroom need to be perceived as positive and supportive in order for peer interactions to make a difference in students' sense of belonging in computing. This is an important question for future research.

While some college experiences were important predictors of belonging, several pre-course experiences and characteristics also emerged as predictors. In fact, students' sense of belonging at 
the start of the introductory course was the strongest predictor of belonging at the end of the course. Similarly, prior experience in computing (e.g., through a course, summer camp, or independently), facilitated sense of belonging during the intro class, even after controlling for incoming belonging scores. These findings underscore the importance of efforts to improve both access and inclusivity within computing at the K-12 level.

Even when controlling for the pretest and prior experience in computing, certain student background characteristics were important predictors of sense of belonging. Key among these was gender. Regardless of the sense of belonging and computing experience that women report at the start of the introductory course, they were less likely than their male counterparts to feel an enhanced sense of belonging in computing by the time the course has ended. In other words, introductory computing courses at these institutions generally did not appear to encourage women's sense of "fit" in their computing environment. Future research will need to address if more progress is made on this front after diversity efforts have been in place longer.

Another noteworthy finding related to students' artistic orientations. Women and URM students who reported a more artistic or creative orientation experienced a greater sense of belonging in computing. This raised the question of whether underrepresented students were more likely to see computing as a vehicle for tapping into their creative inclinations (perhaps this is why they enroll in a computing course in the first place). The role of artistic inclinations in supporting a sense of belonging among women and URM students certainly supports the efforts of those who advocate a view of STEM that is more inclusive of the arts (i.e., "STEAM"). Future research will need to explore whether further emphasizing the creative side of computing via the curriculum or co-curriculum is effective in encouraging diversity in the field.

\subsection{Implications for Practice}

What implications do these findings have for practice in the field of computing? Clearly, it is critical to support efforts that help students—and women and URM students in particular-to develop a sense of belonging in computing prior to college. Current nationwide programs, such as Girls Who Code and Code.org, are just some of the many structures in place to help young women develop a sense of "fit" in the computing world. For URM women in particular, programs such as Black Girls Code and Latina Girls Code hold promise for women to feel like they "belong" in the field of computing. Still, external organizations offering clubs and summer camps are not the only solution. The K-12 sector must take a close look at how all girls, and girls of color in particular, experience the culture of computing within their majority male and White/Asian computing classrooms. Indeed, despite efforts to attract more girls and URM students to computing in K-12, computer science is still not offered in the majority of schools and Advanced Placement (AP) Computer Science courses remain predominantly White, Asian, and male (Code.org 2017). Notably, however, there is greater gender and racial/ethnic diversity in the new AP Computer Science Principles class, a course specifically designed with the goal of enhancing diversity in the computer science talent pool (Code.org 2017). Indeed, after introducing the AP Computer Science Principles course in 2017, the nationwide representation of girls taking AP exams in computer science rose from 23\% (2016) to 27\% (2017). Similarly, the representation of URM students taking AP computer science exams rose from 15\% to 20\% (Code.org 2017). In short, there has been recent progress, but still much left to do before girls and URM students have equitable access to K-12 computing.

This study also reaffirms that, at the college level, environments do matter. While it is not surprising that students who perceive more supportive computing departments feel an enhanced sense of belonging in the field, computing departments must actually take the next steps to becoming more supportive, both for computing majors and those from other majors who take computing courses (see Barker et al. 2014b; Barker and Cohoon 2009). In our study, support was indicated by students' sense that the computing department "cares about its students", fosters a "sense of community", and "inspires me to do the best job that I can". It is important for departments to regularly assess 
whether they are actually accomplishing this, and in particular, whether a sense of belonging is experienced evenly across different groups of students.

Similarly, given the importance of peer support in encouraging a sense of belonging, computing departments must consider the extent to which they are actively fostering a supportive student climate. As indicated by this study, students' sense of belonging is enhanced when they feel that other computing students are available to "hang out" with them, to be a trusted ally, and to provide help understanding course material. The importance of peer support has been documented in decades of research on the impact of college but is often measured in light of students' friends across a variety of majors; this study affirms the specific role of supportive peer groups in the context of the computing major. Considering that merely collaborating with peers in the classroom may not be enough, as noted earlier, departments should consider how they can best encourage students to build meaningful and supportive relationships with each other both in and out of the classroom. In the classroom, instructors can provide structure for how students collaborate with one another, so that they learn how to be supportive colleagues and can work together without fear of cheating (see Fraser 2014). Beyond the classroom, computing departments might consider developing living-learning communities, team-based events (e.g., hack-a-thons), and other activities and organizations to foster community.

Computing departments should also consider the extent to which their curriculum and other programming activities tap into students' own interests and orientations. The fact that sense of belonging in computing is enhanced among women and URM students with more creative and artistic orientations suggests that departments aiming to diversify might even further emphasize the creative applications of computing work. At the same time, departments ought to consider how to promote a greater sense of inclusivity among students with more "communal" orientations (i.e., those who place greater personal importance on collaboration, helping others, and serving communities). Considering that these are the people we arguably need more of in computing, perhaps instructors could incorporate service opportunities to help students connect with others who share similar interests and communal values.

\subsection{Theoretical Implications}

Finally, this study contributes to our theoretical conceptions of sense of belonging in the context of STEM fields. It confirms aspects of the Strayhorn (2012) model (particularly the influence of students' incoming background characteristics and experiences and the salience of environmental contexts) and shows the extent to which the model is applicable to sense of belonging and computing. However, we found that the classroom experiences in our study had relatively little to do with sense of belonging outcomes. Perhaps more nuanced measures of classroom experiences would provide more context for how courses might shape belonging outcomes. Further applying Strayhorn (2012), it may also be the case that our findings are a reflection of the need to consider classroom environments as a mediating force upon classroom experiences; that is, introductory course students do not exist in a vacuum. Rather, students experience outside environments and socio-political forces that influence their classroom experiences. This may require scholars to consider sense of belonging within larger, more inclusive models, such as the multi-contextual model for diverse learning environments, which considers the socio-historical, policy, and institutional contexts, as well as the climate for diversity, community context, and external commitments of the institution (Hurtado et al. 2012). Given the underrepresentation of women and URM students in computing specifically, connecting concepts of sense of belonging to models which address diverse learning environment may provide greater understanding of the complexities present within the computing environment. The study also contributes to the Strayhorn (2012) model by quantitatively examining the predictors of sense of belonging in a discipline where women may feel particularly marginalized and providing at least some evidence of how predictors of sense of belonging may vary by gender or URM status. Future research should examine this theory by considering disciplinary differences to see how sense of belonging might look different for students across different STEM disciplines. 


\subsection{Limitations}

While this study identified student characteristics and college environments that predict sense of belonging in computing, several limitations to the study make it impossible to determine causality. Our study relied on survey data that was collected from students in naturally-occurring educational environments. Research using an experimental design might facilitate our ability to make causal inferences, though experimental design can be difficult to enact in higher education contexts where students have a good degree of control over their course-taking decisions (Astin and antonio 2012). Still, when interpreting the findings from this study, it is important to acknowledge the following limitations.

First, it was difficult to assess how representative our sample was of introductory computing students at the participating institutions since the full characteristics of that population were not known. While we provided participants with incentives to encourage survey response, non-response bias may have still affected our findings. While our initial pretest survey had a moderately high response rate $(32 \%)$, we received longitudinal data for only $11 \%$ of the original sample. Future researchers might consider rewarding students with prepaid incentives, which have been shown to be more effective in increasing response rates (Porter and Whitcomb 2004; Church 1993).

Second, there may be limitations in the extent to which our institutional sample was representative of the broader population of institutions offering introductory computing courses. Compared to a similar survey of computing undergraduates administered to a larger nationwide sample, our sample included proportionately more women and URM students. ${ }^{6}$ Notably, the sample included only students at research universities; future research is needed to examine sense of belonging among computing students at different types of institutions, especially those institutions that tend to enroll more students of color. Researchers should also consider how sense of belonging might develop differently depending on other institutional factors, departmental initiatives, and class size. For example, perhaps students at other institution types are exposed to smaller classes, which may shape the way students develop during the introductory course; this may also explain the lack of significant course environments in the present study. In this particular study, computing department chairs volunteered to be part of the BRAID initiative; thus, these institutions may represent a unique group of schools where the department chair has expressed an interest in diversifying the computing department.

Third, although it is important for researchers to engage with and disseminate findings that disaggregate data across a multitude of identities, this paper was not able to fully do so because of sample size constraints. As a result, regression analyses aggregated students into two racial/ethnic groups: URM and majority. Still, our descriptive analyses reported on disaggregated racial/ethnic groups to the extent possible. In addition, because we know that race/ethnicity and gender may come together to create unique experiences for some students (e.g., women of color), we also tried to capture possible differences across more specific groups (i.e., URM women/men and majority women/men). Related to this is the fact that this study measured sense of belonging in the context of computing and did not capture the larger college environment and related racial climates that might further contribute to a sense of belonging for URM students.

Fourth, this study relied on students' self-reports of their sense of belonging in the computing community. Importantly, students might define the computing community in different ways (e.g., educationally, occupationally, etc.). Future research might take this into account and explore more precise ways to measure sense of belonging in computing. Qualitative research might also explore how students define the computing community and how that shapes their perceived sense of belonging. Further, students reported their sense of belonging on a pretest and post-test; it is possible

6 To assess representativeness, we compared our sample to the students who responded to the 2015 Data Buddies Survey, a national survey of computing students administered by the Computing Research Association. 
that students' exposure to the pretest of sense of belonging prompted them to consider and develop their sense of belonging, thus creating a threat to validity.

Next, because this study utilized interaction terms to test for conditional effects, which consequently privileges main effects in the model (Scott and Siltanen 2012), our findings may not have fully captured how sense of belonging may be shaped by gender or URM status. Finally, this study only examined changes in sense of belonging in computing over the span of one course; future research should examine changes that may occur years after the introductory course.

Finally, future research on this topic might consider using multilevel modeling to capture the way that students are nested in different environments (institutions, computing departments, computing courses, etc.). Multilevel modeling would take into account the standard errors within these different levels. In the present study, we did not have the sample size within these different nested environments to adequately use multilevel modeling. Future research might also examine sense of belonging over a longer period of time (e.g., throughout college and into careers).

\section{Conclusions}

We are at a critical time in the computing field, as interest is rapidly growing and the need for greater diversity is increasingly understood. In addition, discourse around computing no longer focuses just on "numbers" (e.g., of students or employees), but also attends to the notion of "climate" and "inclusion". This study focuses specifically on the extent to which undergraduate students in introductory computing courses feel a sense of belonging in the field of computing, and how that changes over the span of the course. Results highlighted how a sense of belonging in the computing field varied not just by gender and URM status, but by students' value orientations, with weaker belonging found among students with more communal orientations and greater belonging observed among women and URM students with creative/artistic orientations. Further, the study underscored the importance of supportive environments—at both the departmental and peer group level-in fostering students' sense that they belong in the field of computing. An important next step will be to see how important sense of belonging actually is in students' decisions to pursue majors or careers in computing and technology. In addition, future research on the more affective dimensions of the computing experience will benefit from qualitative research and more nuanced measures of college and classroom experiences.

Author Contributions: All authors contributed to the analysis and writing for this paper.

Funding: This work is funded by AnitaB.org, the National Science Foundation (NSF \#1525737), the Computing Research Association (CRA), Facebook, Google, Microsoft, Intel, and Qualcomm.

Acknowledgments: Thank you to Dr. Jane Stout and the Computing Research Association for their partnership in developing our survey instruments.

Conflicts of Interest: The authors declare no conflicts of interest.

\section{Appendix A}

Table A1. Descriptive Statistics for Independent Variables.

\begin{tabular}{lcccc}
\hline & Min. & Max. & Mean & SD \\
\hline BACKGROUND CHARACTERISTICS & & & & \\
\hline $\begin{array}{l}\text { Pretest } \\
\quad \text { Incoming Sense of Belonging }\end{array}$ & -2.930 & 1.641 & 0.000 & 1.000 \\
\hline Demographics & & & & \\
$\quad$ Gender: Woman & 0.000 & 1.000 & 0.439 & 0.497 \\
$\quad$ Race: URM & 0.000 & 1.000 & 0.222 & 0.415 \\
$\quad$ Parents' highest education level & 1.000 & 4.000 & 2.964 & 1.06 \\
$\quad$ Parent computing career & 0.000 & 1.000 & 0.203 & 0.399 \\
$\quad$ Socioeconomic status & 1.000 & 5.000 & 3.190 & 0.890 \\
\hline
\end{tabular}


Table A1. Cont.

\begin{tabular}{lcccc}
\hline & Min. & Max. & Mean & SD \\
\hline Prior Academic Experience & & & & \\
$\quad$ High school GPA & 1.000 & 9.000 & 7.801 & 1.411 \\
$\quad$ Prior programming experience & 0.000 & 6.000 & 1.089 & 1.074 \\
INCOMING ORIENTATIONS & & & & \\
$\quad$ Leadership personality & -2.931 & 2.009 & 0.000 & 1.000 \\
Communal orientation & -3.585 & 1.677 & 0.000 & 1.000 \\
Scholar personality & -3.612 & 1.880 & 0.000 & 1.000 \\
Artistic personality & -2.700 & 2.085 & 0.000 & 1.000 \\
Family orientation & -2.780 & 1.312 & 0.000 & 1.000 \\
\hline COLLEGE ENVIRONMENT VARIABLES & & & & \\
\hline General Support in Computing & & & & \\
$\quad$ Departmental support & -3.156 & 1.773 & 0.000 & 1.000 \\
$\quad$ Peer support & -1.851 & 1.676 & 0.000 & 1.000 \\
\hline Student Behaviors & & & & \\
$\quad$ Hours per week: computing groups & 1.000 & 8.000 & 2.260 & 1.567 \\
$\quad$ Hours per week: studying & 1.000 & 8.000 & 4.970 & 1.562 \\
Hours per week: video/computer games & 1.000 & 8.000 & 3.020 & 1.976 \\
$\quad$ Hours per week: online social networks & 1.000 & 8.000 & 3.540 & 1.635 \\
\hline Classroom Experiences & & & & \\
$\quad$ Collaborative pedagogies & -1.353 & 2.446 & 0.000 & 1.000 \\
$\quad$ Class discussion & 1.000 & 5.000 & 3.040 & 1.226 \\
$\quad$ Lecturing & 1.000 & 5.000 & 4.430 & 0.800 \\
Relevant and meaningful content & -1.250 & 3.210 & 0.000 & 1.000 \\
Instructor inclusivity & -3.732 & 1.439 & 0.000 & 1.000 \\
Student-instructor communication & -1.222 & 4.697 & 0.000 & 1.000 \\
\hline & & & &
\end{tabular}

Table A2. Factor Loadings and/or Coding for all Composite Variables.

\begin{tabular}{ll}
\hline Variable & Factor Loading/Coding Schemes \\
\hline Outcome (Cronbach's alpha $=0.726)$ & \\
\hline I feel like I belong in computing & 0.862 \\
\hline I feel welcomed in the computing community & 0.815 \\
\hline I feel like an outsider in the field of computing (reverse-coded) & 0.734 \\
\hline Pretest (Cronbach's alpha $=0.709)$ & \\
\hline I feel like I belong in computing & 0.854 \\
\hline I feel welcomed in the computing community & 0.793 \\
\hline I feel like an outsider in the field of computing (reverse-coded) & 0.739 \\
\hline Leadership Personality Factor (Cronbach's alpha $=0.771)$ & \\
\hline Self-rating: Public speaking ability & 0.837 \\
\hline Self-rating: Self-Confidence (social) & 0.825 \\
\hline Self-Rating: Leadership ability & 0.823 \\
\hline Communal Orientation Factor (Cronbach's alpha $=0.869)$ & \\
\hline Value: Help others & 0.837 \\
\hline Value: Have a social impact & 0.808 \\
\hline Value: Serve humanity & 0.799 \\
\hline Value: Give back to my community & 0.795 \\
\hline Value: Be a role model for people in my community & 0.792 \\
\hline Value: Work collaboratively with others & 0.638 \\
\hline Scholar Personality Factor (Cronbach's alpha $=0.702)$ & \\
\hline Self-rating: Academic ability & 0.800 \\
\hline Self-rating: Self-Confidence (intellectual) & 0.739 \\
\hline Self-Rating: Mathematical Ability & 0.724 \\
\hline Self-Rating: Drive to achieve & 0.657 \\
\hline & \\
\hline & \\
\hline
\end{tabular}


Table A2. Cont.

\begin{tabular}{|c|c|}
\hline Variable & Factor Loading/Coding Schemes \\
\hline \multicolumn{2}{|l|}{ Artistic Personality Scale (Cronbach's alpha $=0.698$ ) } \\
\hline Self-rating: Creativity & 5-point scale: $1=$ Lowest $10 \% ; 5=$ Highest $10 \%$ \\
\hline Self-rating: Artistic ability & 5-point scale: $1=$ Lowest $10 \% ; 5=$ Highest $10 \%$ \\
\hline \multicolumn{2}{|l|}{ Family Orientation Scale (Cronbach's alpha $=0.818)$} \\
\hline Importance: Spend a lot of time with family & 5-point scale: $1=$ Not at all; $5=$ Extremely \\
\hline Importance: Take time off work to care for my family & 5-point scale: $1=$ Not at all; $5=$ Extremely \\
\hline \multicolumn{2}{|l|}{ Department Support Factor (Cronbach's alpha $=0.795)$} \\
\hline The department cares about its students & 0.905 \\
\hline $\begin{array}{l}\text { The environment in the computing department inspires me to do the best } \\
\text { job that I can }\end{array}$ & 0.896 \\
\hline I feel a sense of community in the computing department & 0.855 \\
\hline The department is not very supportive of its students (reverse-coded) & 0.489 \\
\hline \multicolumn{2}{|l|}{ Computing Peer Support Factor (Cronbach's alpha $=0.901$ ) } \\
\hline $\begin{array}{l}\text { To what extent is each of the following kinds of support available to you } \\
\text { from other computing students if you need it: Someone to hang out with }\end{array}$ & 0.897 \\
\hline $\begin{array}{l}\text { To what extent is each of the following kinds of support available to you } \\
\text { from other computing students if you need it: Someone to confide in or talk } \\
\text { to about your problems }\end{array}$ & 0.879 \\
\hline $\begin{array}{l}\text { To what extent is each of the following kinds of support available to you } \\
\text { from other computing students if you need it: Someone to get class } \\
\text { assignments for you if you were sick }\end{array}$ & 0.870 \\
\hline $\begin{array}{l}\text { To what extent is each of the following kinds of support available to you } \\
\text { from other computing students if you need it: Someone to help you } \\
\text { understand difficult homework problems }\end{array}$ & 0.869 \\
\hline \multicolumn{2}{|l|}{ Collaborative Pedagogies Factor (Cronbach's alpha $=0.695$ ) } \\
\hline $\begin{array}{l}\text { How frequently does the instructor(s) for this introductory course use the } \\
\text { following: Paired programming }\end{array}$ & 0.848 \\
\hline $\begin{array}{l}\text { How frequently does the instructor(s) for this introductory course use the } \\
\text { following: Group work }\end{array}$ & 0.847 \\
\hline $\begin{array}{l}\text { How frequently does the instructor(s) for this introductory course use the } \\
\text { following: Peer instruction }\end{array}$ & 0.661 \\
\hline \multicolumn{2}{|l|}{ Use of Relevant and Meaningful Content Factor (Cronbach's alpha $=0.808$ ) } \\
\hline $\begin{array}{l}\text { How frequently does the instructor(s) for this introductory course use the } \\
\text { following: Use of examples involving women }\end{array}$ & 0.892 \\
\hline $\begin{array}{l}\text { How frequently does the instructor(s) for this introductory course use the } \\
\text { following: Use of examples involving people of color }\end{array}$ & 0.890 \\
\hline $\begin{array}{l}\text { How frequently does the instructor(s) for this introductory course use the } \\
\text { following: Interdisciplinary connections to computer science (e.g., biology } \\
\text { and computer science) }\end{array}$ & 0.733 \\
\hline $\begin{array}{l}\text { How frequently does the instructor(s) for this introductory course use the } \\
\text { following: Use of real world problems involving relevant social issues }\end{array}$ & 0.679 \\
\hline \multicolumn{2}{|l|}{ Instructor Inclusivity and Support Factor (Cronbach's alpha $=0.907$ ) } \\
\hline Introductory course faculty are inclusive and supportive of women & 0.885 \\
\hline Introductory course faculty are responsive to questions in class & 0.869 \\
\hline $\begin{array}{l}\text { Introductory course faculty are interested in helping me when I come to } \\
\text { them with questions }\end{array}$ & 0.868 \\
\hline $\begin{array}{l}\text { Introductory course faculty are inclusive and supportive of students } \\
\text { of color }\end{array}$ & 0.865 \\
\hline Introductory course faculty are responsive to email communication & 0.781 \\
\hline \multicolumn{2}{|l|}{ Prior Programming Experience Scale } \\
\hline $\begin{array}{l}\text { I took a computer programming course in high school (e.g., Java, Python, } \\
\text { HTML, etc.) }\end{array}$ & $1=$ Unselected; 2 = Selected \\
\hline I took a computer programming course at computer camp & $1=$ Unselected; 2 = Selected \\
\hline
\end{tabular}


Table A2. Cont.

\begin{tabular}{|c|c|}
\hline Variable & Factor Loading/Coding Schemes \\
\hline I took a computer programming course online & $1=$ Unselected; 2 = Selected \\
\hline I took a computer programming course at this college & 1 = Unselected; 2 = Selected \\
\hline I took a computer programming course at another four-year college & $1=$ Unselected; 2 = Selected \\
\hline I took a computer programming course at community college & 1 = Unselected; 2 = Selected \\
\hline $\begin{array}{l}\text { I did not take a specific course, but I learned to program on my own (e.g., } \\
\text { by reading books) }\end{array}$ & 1=Unselected; $2=$ Selected \\
\hline \multicolumn{2}{|l|}{ Frequency of Instructor Communication Scale (Cronbach's alpha $=0.816)$} \\
\hline $\begin{array}{l}\text { On average, how frequently do you communicate with introductory course } \\
\text { faculty for this course in the following way: In class }\end{array}$ & $\begin{array}{l}\text { 5-point scale: } 1=\text { Never; } 5=\text { More than three } \\
\text { times per week }\end{array}$ \\
\hline $\begin{array}{l}\text { On average, how frequently do you communicate with introductory course } \\
\text { faculty for this course in the following way: At office hours }\end{array}$ & $\begin{array}{l}5 \text {-point scale: } 1=\text { Never; } 5=\text { More than three } \\
\text { times per week }\end{array}$ \\
\hline $\begin{array}{l}\text { On average, how frequently do you communicate with introductory course } \\
\text { faculty for this course in the following way: By text messages }\end{array}$ & $\begin{array}{l}5 \text {-point scale: } 1=\text { Never; } 5=\text { More than three } \\
\text { times per week }\end{array}$ \\
\hline $\begin{array}{l}\text { On average, how frequently do you communicate with introductory course } \\
\text { faculty for this course in the following way: Via course website } \\
\text { (e.g., Blackboard) }\end{array}$ & $\begin{array}{l}5 \text {-point scale: } 1=\text { Never; } 5=\text { More than three } \\
\text { times per week }\end{array}$ \\
\hline $\begin{array}{l}\text { On average, how frequently do you communicate with introductory course } \\
\text { faculty for this course in the following way: In informal meetings } \\
\text { (e.g., coffee with a professor) }\end{array}$ & $\begin{array}{l}5 \text {-point scale: } 1=\text { Never; } 5=\text { More than three } \\
\text { times per week }\end{array}$ \\
\hline
\end{tabular}

Table A3. Blocked Regression Predicting Sense of Belonging (Changes in Coefficients).

\begin{tabular}{|c|c|c|c|c|c|c|}
\hline Variable & Model 1 & Model 2 & Model 3 & Model 4 & Model 5 & Model 6 \\
\hline Pretest & 0.721 & 0.693 & 0.666 & 0.666 & 0.530 & 0.521 \\
\hline Gender (Female) & & -0.107 & -0.101 & -0.101 & -0.108 & -0.393 \\
\hline URM & & 0.021 & 0.016 & 0.018 & 0.016 & -0.194 \\
\hline Prior Programming Experience & & & 0.088 & 0.084 & 0.096 & 0.098 \\
\hline Communal Orientation & & & & -0.026 & -0.072 & -0.070 \\
\hline Artistic Orientation & & & & 0.034 & 0.048 & -0.037 \\
\hline Departmental Support & & & & & 0.277 & 0.278 \\
\hline Peer Support & & & & & 0.065 & 0.063 \\
\hline Artistic Orientation*URM & & & & & & 0.224 \\
\hline Artistic Orientation ${ }^{*}$ Gender & & & & & & 0.303 \\
\hline Model $\mathrm{R}^{2}$ & 0.521 & 0.532 & 0.538 & 0.540 & 0.615 & 0.622 \\
\hline
\end{tabular}

Note: Bold indicates significance at the $p<0.01$ level. Bolded $\mathrm{R}^{2}$ indicates a significant change in $R^{2}$.

\section{References}

Alvarado, Christine, Zachary Dodds, and Ran Libeskind-Hadas. 2012. Increasing Women's Participation in Computing at Harvey Mudd College. ACM Inroads 3: 55-64. [CrossRef]

Astin, Alexander W., and anthony lising antonio. 2012. Assessment for Excellence: The Philosophy and Practice of Assessment and Evaluation in Higher Education, 2nd ed. Lanham: Rowman \& Littlefield Publishers, Inc.

Barker, Lecia J., and Joanne McGrath Cohoon. 2009. Key Practices for Retaining Undergraduates in Computing. Available online: http:/ / www.ncwit.org/resources/key-practices-retaining-undergraduates-computing (accessed on 10 October 2017).

Barker, Lecia J., Charlie McDowell, and Kimberly Kalahar. 2009. Exploring Factors that Influence Computer Science Introductory Course Students to Persist in the Major. Paper presented at 40th SIGCSE Technical Symposium on Computer Science Education, Chattanooga, TN, USA, March 3-7. 
Barker, Lecia J., Joanne McGrath Cohoon, and Leisa D. Thompson. 2010. Work in progress-A practical model for achieving gender parity in undergraduate computing: Change the system, not the student. Paper presented at the 2010 IEEE Frontiers in Education Conference (FIE), Washington, DC, USA, October 27-30; New York: IEEE, p. S1H-1.

Barker, Lecia J., Christopher L. Hovey, and Leisa D. Thompson. 2014a. Results of a large-scale, multi-institutional study of undergraduate retention in computing. Paper presented at the 2014 IEEE Frontiers in Education Conference (FIE), Madrid, Spain, October 22-25; New York: IEEE, pp. 1-8.

Barker, Lecia J., Melissa O'Neill, and Nida Kazim. 2014b. Framing Classroom Climate for Student Learning and Retention in Computer Science. Paper presented at 45th ACM Technical Symposium on Computer Science Education, Atlanta, GA, USA, March 5-8.

Baumeister, Roy F., and Mark R. Leary. 1995. The Need to Belong: Desire for Interpersonal Attachment as a Fundamental Human Motivation. Psychological Bulletin 117: 497-529. [CrossRef] [PubMed]

Beyer, Sylvia. 2014. Why are Women Underrepresented in Computer Science? Gender Differences in Stereotypes, Self-Efficacy, Values, and Interests and Predictors of Future CS Course-Taking and Grades. Computer Science Education 24: 153-92. [CrossRef]

Beyer, Sylvia, Kristina Rynes, Julie Perrault, Kelly Hay, and Susan Haller. 2003. Gender Differences in Computer Science Students. Paper presented at 34th SIGCSE Technical Symposium on Computer Science Education, Reno, NV, USA, February 19-23.

Beyer, Sylvia, Kristina Rynes, and Susan Haller. 2004. Deterrents to Women Taking Computer Science Courses. IEEE Technology and Society Magazine 23: 21-28. [CrossRef]

Blaney, Jennifer M., and Jane G. Stout. 2017. Examining the Relationship between Introductory Computing Course Experiences, Self-Efficacy, and Belonging among First-Generation College Women. Paper Presented at 48th SIGCSE Technical Symposium on Computer Science Education, Seattle, WA, USA, March 8-11.

Carter, Lori. 2006. Why Students with an Apparent Aptitude for Computer Science Don't Choose to Major in Computer Science. ACM SIGCSE Bulletin 38: 27-31. [CrossRef]

Cheryan, Sapna, Victoria C. Plaut, Paul G. Davies, and Claude M. Steele. 2009. Ambient Belonging: How Stereotypical Cues Impact Gender Participation in Computer Science. Journal of Personality and Social Psychology 97: 1045-60. [CrossRef] [PubMed]

Cheryan, Sapna, Benajmin J. Drury, and Marissa Vichayapai. 2013. Enduring Influence of Stereotypical Computer Science Role Models on Women's Academic Aspirations. Psychology of Women Quarterly 37: 72-79. [CrossRef]

Cheryan, Sapna, Sianna A. Ziegler, Amanda K. Montoya, and Lily Jiang. 2016. Why are Some STEM Fields More Gender Balanced than Others? Psychological Bulletin 143: 1-35. [CrossRef] [PubMed]

Chu, Hyon S. 2017. New Technology Industry Diversity \& Inclusion Report 2017. Available online: http: / / hello.cultureamp.com/diversity-and-inclusion (accessed on 10 October 2017).

Church, Allan H. 1993. Estimating the Effect of Incentives on Mail Survey Response Rates: A Meta-Analysis. Public Opinion Quarterly 57: 62-79. [CrossRef]

Code.org. 2017. Girls Set AP Computer Science Record ... Skyrocketing Growth Outpaces Boys. Medium. Available online: https:/ / medium.com/@codeorg/girls-set-ap-computer-science-record-skyrocketinggrowth-outpaces-boys-41b7c01373a5 (accessed on 10 October 2017).

Cohoon, Joanne McGrath. 2002. Recruiting and retaining women in undergraduate computing majors. ACM SIGCSE Bulletin 34: 48-52. [CrossRef]

Cohoon, Joanne McGrath, and William Aspray. 2008. A Critical Review of the Research on Women's Participation in Postsecondary Computing Education. In Women and Information Technology: Research on Underrepresentation. Edited by J. McGrath Cohoon and William Aspray. Cambridge: MIT Press, pp. 137-80.

Diekman, Amanda B., Elizabeth R. Brown, Amanda M. Johnston, and Emily K. Clark. 2010. Seeking Congruity between Goals and Roles: A New Look at Why Women Opt Out of Science, Technology, Engineering, and Mathematics Careers. Psychological Science 21: 1051-57. [CrossRef] [PubMed]

Espinosa, Lorelle. 2011. Pipelines and Pathways: Women of Color in Undergraduate STEM Majors and the College Experiences that Contribute to Persistence. Harvard Educational Review 81: 209-41. [CrossRef]

Fraser, Robert. 2014. Collaboration, Collusion and Plagiarism in Computer Science Coursework. Informatics in Education 13: 179-95. [CrossRef]

Freeman, Tiera M., Lynley H. Anderman, and Jane M. Jensen. 2007. Sense of Belonging in College Freshmen at the Classroom and Campus Levels. The Journal of Experimental Education 75: 203-20. [CrossRef] 
Gasiewski, Jo A., Kevin Eagan, Gina A. Garcia, Sylvia Hurtado, and Mitchell J. Chang. 2012. From Gatekeeping to Engagement: A Multicontextual, Mixed Method Study of Student Academic Engagement in Introductory STEM Courses. Research in Higher Education 53: 229-61. [CrossRef] [PubMed]

Good, Catherine, Aneeta Rattan, and Carol S. Dweck. 2012. Why do Women Opt Out? Sense of Belonging and Women's Representation in Mathematics. Journal of Personality and Social Psychology 102: 700-17. [CrossRef] [PubMed]

Goodenow, Carol. 1993. Classroom Belonging among Early Adolescent Students: Relationships to Motivation and Achievement. Journal of Early Adolescence 13: 21-43. [CrossRef]

Graham, Mark J., Jennifer Frederick, Angela Byars-Winston, Anne-Barrie Hunter, and Jo Handelsman. 2013. Increasing Persistence of College Students in STEM. Science 341: 1455-56. [CrossRef] [PubMed]

Hoffman, Marybeth, Jayne Richmond, Jennifer Morrow, and Kandice Salomone. 2002. Investigating "Sense of Belonging" in First-Year College Students. Journal of College Student Retention: Research, Theory E Practice 4: 227-56.

Hoisch, Thomas D., and James I. Bowie. 2010. Assessing Factors that Influence the Recruitment of Majors from Introductory Geology Classes at Northern Arizona University. Journal of Geoscience Education 58: 166-76. [CrossRef]

Hurtado, Sylvia, and Deborah Faye Carter. 1997. Effects of College Transition and Perceptions of the Campus Racial Climate on Latino College Students' Sense of Belonging. Sociology of Education 70: 324-45. [CrossRef]

Hurtado, Sylvia, Cynthia L. Alvarez, Chelsea Guillermo-Wann, Marcela Cuellar, and Lucy Arellano. 2012. A Model for Diverse Learning Environments. In Higher Education: Handbook of Theory and Research. Edited by John C. Smart and Michael B. Paulsen. New York: Springer, vol. 27, pp. 41-122.

Johnson, Dawn R. 2012. Campus Racial Climate Perceptions and Overall Sense of Belonging among Racially Diverse Women in STEM Majors. Journal of College Student Development 53: 336-46. [CrossRef]

Johnson, Dawn R., Mathew Soldner, Jeannie Brown Leonard, Patty Alvarez, Karen Kurotsuchi Inkelas, Heather T. Rowan-Kenyon, and Susan D. Longerbeam. 2007. Examining Sense of Belonging among First-Year Undergraduates from Different Racial/Ethnic Groups. Journal of College Student Development 48: 525-42. [CrossRef]

Lewis, Karyn L., Jane G. Stout, Steven J. Pollock, Noah D. Finkelstein, and Tiffany A. Ito. 2016. Fitting In or Opting Out: A Review of Key Social-Psychological Factors Influencing a Sense of Belonging for Women in Physics. Physical Review Physics Education Research 12: 1-10. [CrossRef]

Locks, Angela M., Sylvia Hurtado, Nicholas A. Bowman, and Leticia Oseguera. 2008. Extending Notions of Campus Climate and Diversity to Students' Transition to College. The Review of Higher Education 31: 257-85. [CrossRef]

Margolis, Jane, and Allan Fisher. 2002. Unlocking the Clubhouse: Women in Computing. Cambridge: The MIT Press. Margolis, Jane, Rachel Estrella, Joanna Goode, Jennifer J. Holme, and Kimberly Nao. 2008. Stuck in the Shallow End: Education, Race, and Computing. Cambridge: The MIT Press.

Mitchell, Sidney Kirk. 2011. Factors that Contribute to Persistence and Retention of Underrepresented Minority Undergraduate Students in Science, Technology, Engineering, and Mathematics (STEM). Ph.D. dissertation, University of Southern Mississippi, Hattiesburg, MS, USA, August.

National Center for Education Statistics. 2017. Digest of Education Statistics: Bachelor's Degrees Conferred by Postsecondary Institutions, by Race/Ethnicity and Sex of Student: Selected Years, 1976-77 through 2015-2016. Available online: https://nces.ed.gov/programs/digest/d17/tables/dt17_322.20.asp?current=yes (accessed on 10 October 2017).

National Science Foundation, National Center for Science and Engineering Statistics. 2017a. Integrated Postsecondary Education Data System (IPEDS) Completion Survey by Race, Integrated Science and Engineering Resources Data System (WebCASPAR). Available online: https:/ /ncsesdata.nsf.gov/webcaspar/ (accessed on 10 October 2017).

National Science Foundation. 2017b. Women, Minorities, and Persons with Disabilities in Science and Engineering. Available online: https:/ / www.nsf.gov/statistics/2017/nsf17310/ (accessed on 18 July 2018).

Nuñez, Anne-Marie. 2009. A Critical Paradox? Predictors of Latino Students' Sense of Belonging in College. Journal of Diversity in Higher Education 2: 46. [CrossRef] 
Perna, Laura, Valerie Lundy-Wagner, Noah D. Drezner, Marybeth Gasman, Susan Yoon, Enakshi Bose, and Shannon Gary. 2009. The Contribution of HBCUs to the Preparation of African American Women for STEM Careers: A Case Study. Research in Higher Education 50: 1-23. [CrossRef]

Pittman, Laura D., and Adeya Richmond. 2008. University Belonging, Friendship Quality, and Psychological Adjustment during the Transition to College. The Journal of Experimental Education 76: 343-62. [CrossRef]

Porter, Stephen R., and Michael E. Whitcomb. 2004. Understanding the effect of prizes on response rates. New Directions for Institutional Research 121: 51-62. [CrossRef]

Radermacher, Alex D., and Gursimran S. Walia. 2011. Investigating the Effective Implementation of Pair Programming: An Empirical Investigation. Paper presented at 42nd ACM Technical Symposium on Computer Science Education, Dallas, TX, USA, March 9-12.

Scott, Nick, and Janet Siltanen. 2012. Gender and Intersectionality: A Quantitative Toolkit for Analyzing Complex Inequalities. Employment and Social Development Canada. Available online: http:/ /www.janetsiltanen.ca/ toolkitenglish.pdf (accessed on 10 October 2017).

Settle, Amber. 2012. Turning the Tables: Learning from Students about Teaching CS1. Paper presented at the 13th Annual Conference on Information Technology Education, Calgary, AB, Canada, October 11-13.

Seymour, Elaine, and Nancy M. Hewitt. 1997. Talking about Leaving: Why Undergraduates Leave the Sciences. Boulder: Westview Press.

Smith, Jessi L., Erin Cech, Anneke Metz, Meghan Huntoon, and Christina Moyer. 2014. Giving Back or Giving up: Native American Student Experiences in Science and Engineering. Cultural Diversity and Ethnic Minority Psychology 20: 413. [CrossRef] [PubMed]

Strayhorn, Terrell L. 2008. Fittin'In: Do Diverse Interactions with Peers Affect Sense of Belonging for Black Men at Predominantly White Institutions? NASPA Journal 45: 501-27.

Strayhorn, Terrell Lamont. 2012. College Students' Sense of Belonging: A Key to Educational Success for All Students. New York: Routledge.

Suresh, Radhika. 2006. The Relationship between Barrier Courses and Persistence in Engineering. Journal of College Student Retention: Research, Theory E Practice 8: 215-39.

Tamer, Burcin, and Jane G. Stout. 2016. Recruitment and Retention of Undergraduate Students in Computing: Patterns by Gender and Race/Ethnicity. Computing Research Association. Available online: https:/ / cra. org/cerp/research-findings/ (accessed on 18 July 2018).

Thoman, Dustin B., Jessica A. Arizaga, Jessi L. Smith, Tyler S. Story, and Gretchen Soncuya. 2014. The Grass is Greener in Non-Science, Technology, Engineering, and Math Classes: Examining the Role of Competing Belonging to Undergraduate Women's Vulnerability to Being Pulled away from Science. Psychology of Women Quarterly 38: 246-58. [CrossRef]

Tobias, Sheila. 1990. Stemming the science shortfall at college. In They're Not Dumb, They're Different: Stalking the Second Tier. Edited by Sheila Tobias. Tuscon: Research Corporation, pp. 7-18.

Veilleux, Nanette, Rebecca Bates, Diane Jones, Cheryl Allendoerfer, and Joy Crawford. 2012. The Role of Belonging in Engagement, Retention, and Persistence. Paper presented at 43rd ACM Technical Symposium on Computer Science Education, Raleigh, NC, USA, February 29-March 3.

Walton, Gregory M., and Geoffrey L. Cohen. 2007. A Question of Belonging: Race, Social Fit, and Achievement. Journal of Personality and Social Psychology 92: 82-96. [CrossRef] [PubMed]

Werner, Linda L., Brian Hanks, Charlie McDowell, Heather Bullock, and Julian Fernald. 2005. Want to Increase Retention of your Female Students? Computing Research News 17: 2.

Wilson, Brenda Cantwell. 2002. A Study of Factors Promoting Success in Computer Science Including Gender Differences. Computer Science Education 12: 141-64. [CrossRef]

(C) 2018 by the authors. Licensee MDPI, Basel, Switzerland. This article is an open access article distributed under the terms and conditions of the Creative Commons Attribution (CC BY) license (http:/ / creativecommons.org/licenses/by/4.0/). 